\title{
Spinal Angiolipomas : Clinical Characteristics, Surgical Strategies and Prognosis
}

\author{
Xiaolei Zhang, Sheng Dong, Guoqin Wang, Huifang Zhang, James Jin Wang, Guihuai Wang \\ Department of Neurosurgery, Beijing Tsinghua Changgung Hospital, School of Clinical Medicine, Tsinghua University, Beijing, China
}

Objective : Angiolipomas are usually found in the subcutaneous tissue of the trunk and limbs. Spinal angiolipomas (SALs) are uncommon and have rarely been reported. We report a series of nine SALs patients who received surgical treatment in our department. To summarize the clinical characteristics of SALs, propose our surgical strategies, and evaluate the effects of the operation.

Methods : This was a retrospective review of nine SALs patients who received surgical treatment from August 2015 to March 2020. Total or subtotal resection was determined by the axial localization (dorsal or ventral) and the extent of intervertebral foramen involvement. The outcomes were assessed based on the modified Japanese Orthopaedic Association (mJOA) scoring system utilized before surgery and at various follow-up points.

Results : Among the nine patients, the mean $\mathrm{mJOA}$ score before surgery was $6.6 \pm 2.3$, compared with $10.1 \pm 1.1$ at the last follow-up time point (33.4 \pm 11.8 months). All patients achieved good outcomes, even in cases of subtotal resection.

Conclusion : Early surgical resection of SALs is recommended, and the specific procedures should be determined by the axial localization (dorsal or ventral) and the extent of intervertebral foramen involvement. Most of the patients had a good prognosis, even in cases of subtotal resection.

Key Words : Angiolipoma, spine · Diagnosis · Surgery · Prognosis.

\section{INTRODUCTION}

Angiolipomas are benign tumors composed of mature fatty tissue and abnormal vascular elements, and they are usually found in the subcutaneous tissue of the trunk and limbs ${ }^{5}$. Spinal angiolipomas (SALs) are uncommon in the clinic and have rarely been reported in the literature. Because of this low occurrence, reports are always case reports. In this article, we report a series of nine SALs patients to summarize their clini- cal characteristics and evaluate the surgical strategies and the effects of the operation.

\section{MATERIALS AND METHODS}

This study was approved by the Ethics Committee of Beijing Tsinghua Changgung Hospital (18013-0-01). This type of study does not require informed consent.

- Received : January 4, $2021 ・$ Revised : March 18, 2021 •Accepted : April 7, 2021

- Address for reprints : Guihuai Wang

Department of Neurosurgery, Beijing Tsinghua Changgung Hospital, School of Clinical Medicine, Tsinghua University, No.168 Litang Road, Changping District, Beijing 102218, China Tel : +86-1056119530, Fax : +86-105611953, E-mail : wghneurosurgeon@126.com, ORCID : https://orcid.org/0000-0002-9254-5088 


\section{General information}

Nine patients with SALs (confirmed by final pathological results) were retrospectively reviewed at our center from $\mathrm{Au}-$ gust 2015 to March 2020. Those patients included four males and five females aged $12-73$ years ( $46.6 \pm 17.9$ years). The mean disease duration (history before diagnosis) was 15.1 \pm 19.1 months (range, 2-60), and the SALs locations included thoracic segments $(n=5)$, lumbar segments $(n=3)$, and cervical segments $(\mathrm{n}=1)$. Regarding the clinical symptoms, the patients' complaints were mostly sensory disorders (numbness, paresthesia, and pain), motor deficits (limb weakness) and sphincter disturbances. None of the patients underwent invasive treatment before the operation. The patients' general information is listed in Table 1.

\section{Radiological classification}

According to the classification methods proposed by Lin and $\operatorname{Lin}^{15}$, we had seven noninfiltrating SALs cases and two infiltrating SALs cases. The different subtypes of SALs are shown in Fig. 1.

\section{Surgical management}

Electrophysiological monitoring, including somatosensoryevoked potentials and motor-evoked potentials, was used during every operation. The operations were performed with the patient in a semiprone position and with a posterior midline incision. The vertebral laminae of the corresponding lesion segments were removed to provide adequate exposure of the tumors.

In cases with a dorsal location and those in which the intervertebral foramens were not seriously affected, total resection of the tumors and the capsule was achievable. On the other hand, if the tumors had a ventral location or if the intervertebral foramens were seriously affected, wider resection was performed.

After resection of the tumors, the laminae were replaced and fixed with plates and screws to reconstruct the stability of the spine. Radiotherapy and chemotherapy were not administered after routine surgery, even in cases of subtotal resection.

The tumors were examined by two independent experienced pathologists after the surgery.

\section{Outcome evaluation}

The outcomes were assessed based on the modified Japa-

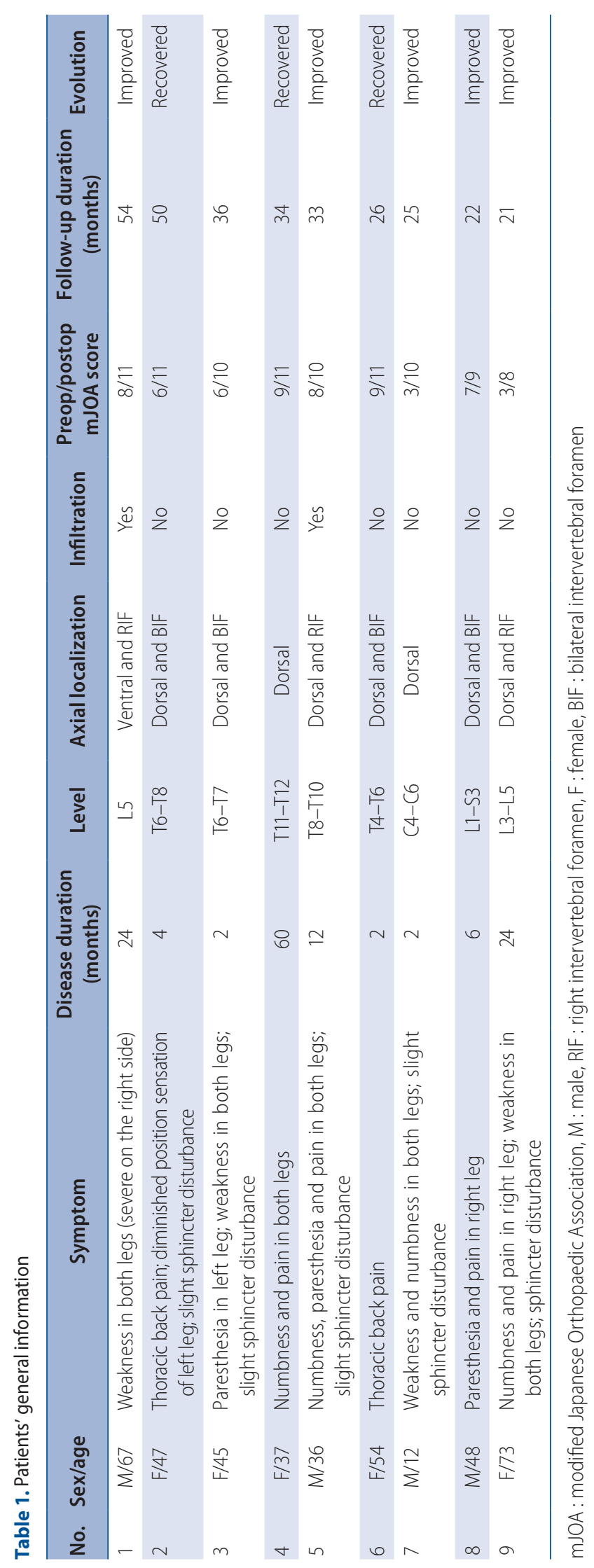



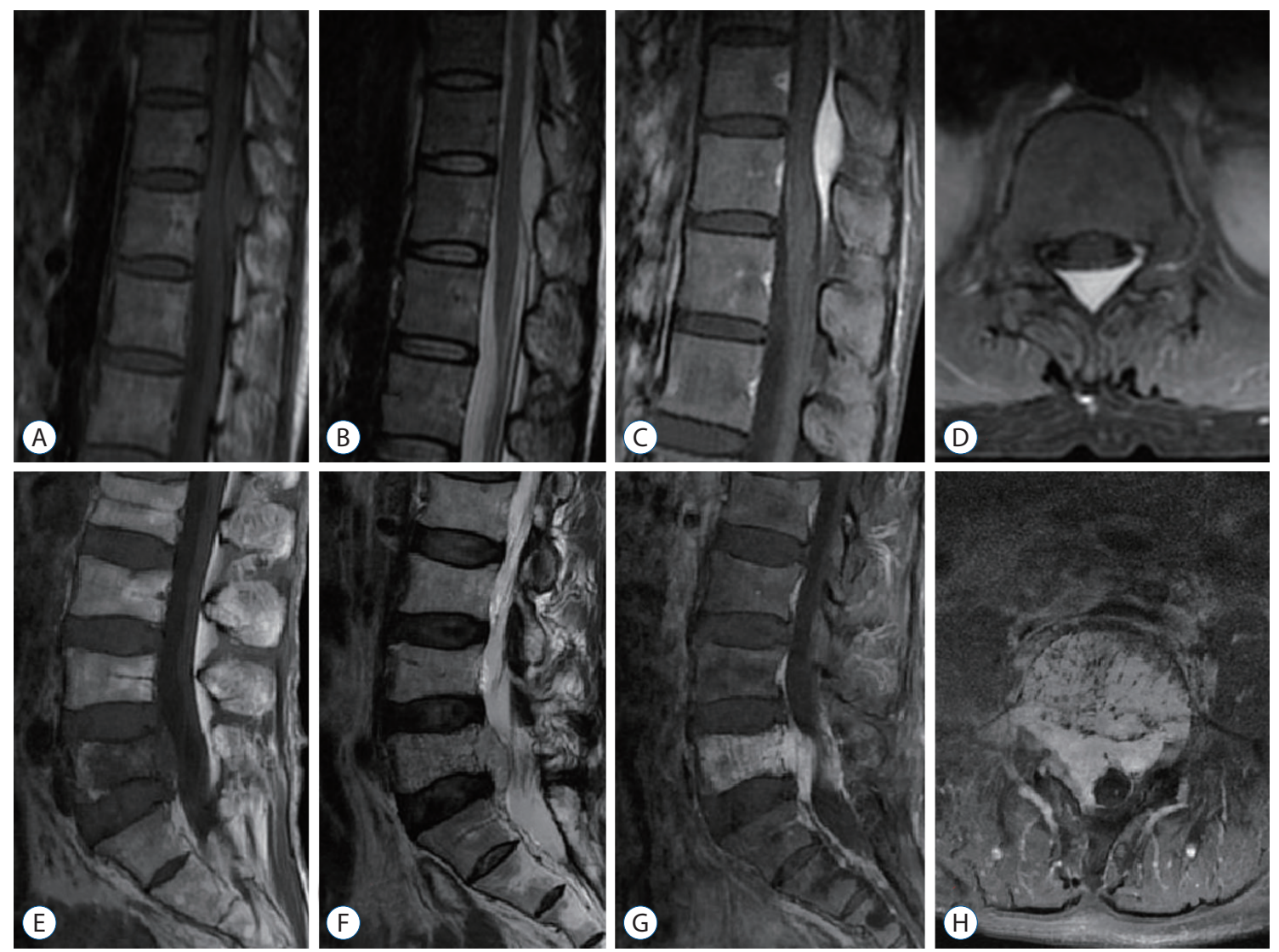

Fig. 1. A-D : It presents the magnetic resonance imaging (MRI) scans of patient No. 4. The dorsally located epidural mass (T11-T12) was isointense on T1weighted images $(\mathrm{WI})$, hyperintense on $\mathrm{T} 2 \mathrm{WI}$, and homogeneously enhanced on contrast-enhanced images. $\mathrm{E}-\mathrm{H}$ : It presents the MRI scans of patient No. 1. The mass was located in the ventral part, and the vertebral body (L5) and right intervertebral foramen were also affected. The mass and the affected vertebral body were hypointense on T1WI, hyperintense on T2WI, and inhomogeneously enhanced on contrast-enhanced images. A and E : Sagittal T1WI. B and F : Sagittal T2WI. C and G : Sagittal contrast-enhanced image. D and H : Axial contrast-enhanced image.

nese Orthopaedic Association (mJOA) scoring system before and 3, 6, and 12 months after the surgery and then once every 12 months. The mean follow-up period was $33.4 \pm 11.8$ months (range, 21-54).

\section{Statistical analysis}

Data are expressed as the mean \pm standard deviation. The mJOA scores before and after surgery were compared using ttest. All statistical analyses were performed using SPSS (version 17.0; SPSS Inc., Chicago, IL, USA), and $p<0.05$ was used to determine statistical significance.

\section{RESULTS}

Among the nine patients analyzed, the mJOA score was 6.6 \pm 2.3 before surgery and $10.1 \pm 1.1$ at the last follow-up time point ( $p<0.001$, t-test). Total resection (confirmed by intraoperative discovery and follow-up magnetic resonance imaging [MRI] scans) of the tumors was achieved in seven patients, and subtotal resection was achieved in two patient (No. 1 and 5). At the last follow-up time point, three patients exhibited recovery, six patients exhibited improvement, and no recurrence was observed in any patients. Some of the postoperative MRI scans are shown in Fig. 2.

According to the histological examination, the tissue was composed of mature lipocytes and abnormal blood vessels, consistent with a diagnosis of angiolipoma (Fig. 3).

Immunohistochemistry was performed in seven patients. The main results were CD31 (+), 6/7; CD34 (+), 6/7; S-100 (+), 5/7; Ki-67 (+), 4/7, <3\%. 

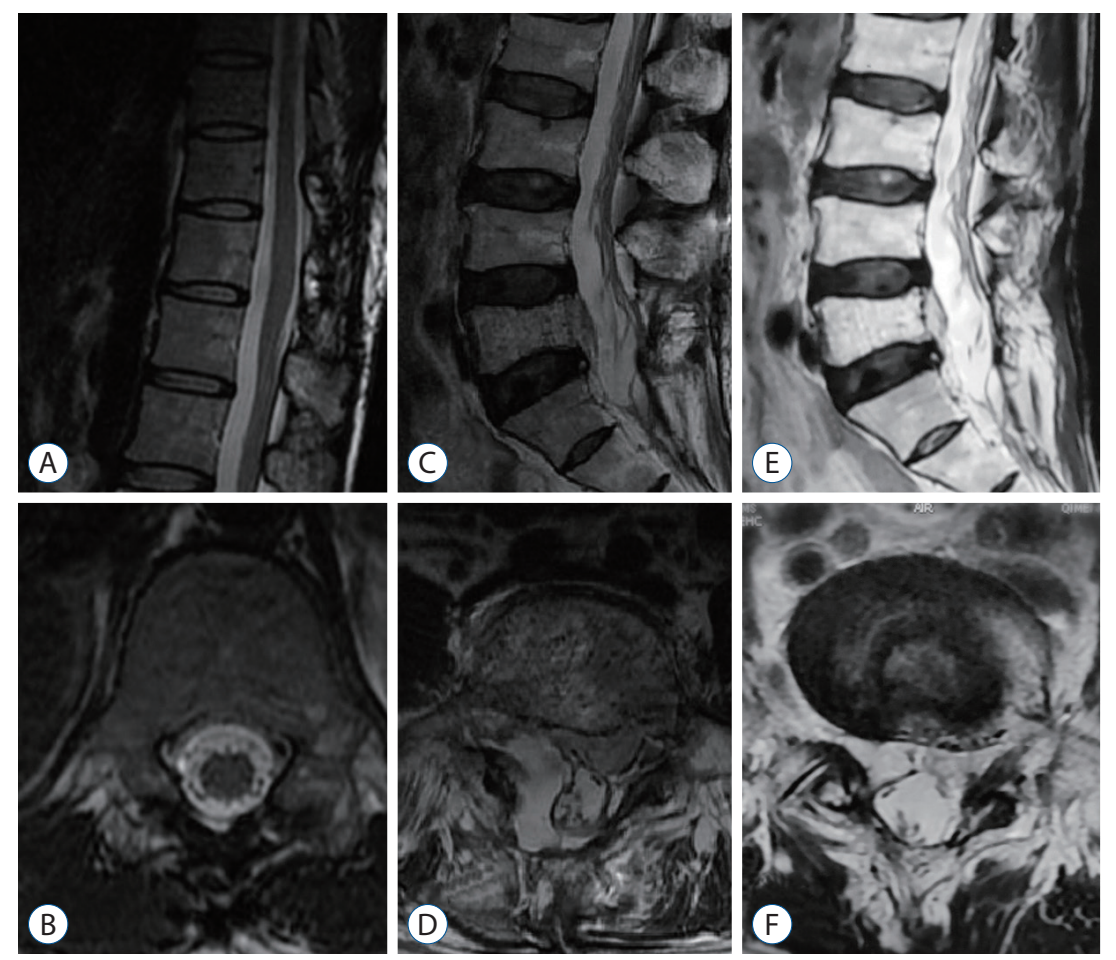

Fig. 2. A and B : It presents the postoperative the magnetic resonance imaging (MRI) scans (2 years after surgery) of patient No. 4. MRI shows that the tumors were completely removed without recurrence. C-F : It presents the postoperative MRI (1 month and 4 years after surgery) scans of patient No. 1. The results show that the tumors were partially removed, and there was no sign of further growth. A : Sagittal T2WI. B : Axial T2WI. C : Sagittal T2WI 1 month after surgery. D : Axial T2WI 1 month after surgery. E : Sagittal T2WI 4 years after surgery. F : Axial T2WI 4 years after surgery.
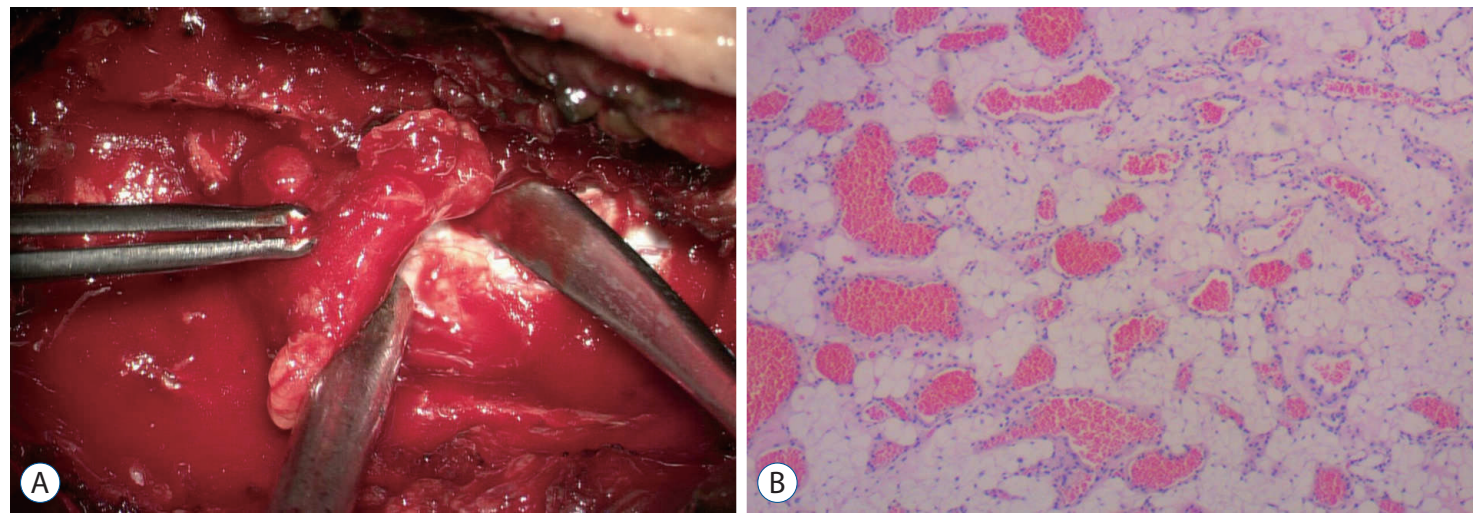

Fig. 3. A : Intraoperative photo. The tumors were mainly composed of adipose tissue mixed with vascular structures that easily bled. B : Photomicrograph. The tumor was composed of mature adipose tissue and proliferating vascular elements ( $\mathrm{H} \& \mathrm{E}$, original magnification $\times 40$ ).

\section{DISCUSSION}

SALs were first reported by Berenbruch in $1890^{1)}$. In 1960, Howard and Helwig ${ }^{10)}$ described SALs as anatomopathologic entities containing vascular and mature adipose elements.

\section{Demographic characteristics}

As reported in previous studies, SALs are considered benign and rare lesions of the spinal axis, and they account for 0.14$1.2 \%$ of all spinal tumors and $2-3 \%$ of epidural spinal tumors ${ }^{4,12,18}$. SALs occur mostly in adults aged between 40 and 60 years and have a female predominance, and the duration of disease is usually long. The most common site of SALs is the 
posterior epidural space at the thoracic level, and multiple segments are often involved ${ }^{6,14,23,28)}$.

The thoracic predominance of SALs was also found in our series of patients (5/9). This could be explained by the regional variation of the blood supply in the mid-thoracic spine, where the spine is least perfused. This may allow spinal lipomas to transform into SALs because of neovascularization caused by possible ischemic events ${ }^{13)}$

We also noted some differences in our series. 1) We had a 12-year-old cervical SALs (C4-C6) patient (No. 7) with a relatively short disease duration (2 months). This situation has also been reported in other studies ${ }^{7,24)}$, but we did not find spontaneous epidural hematomas during surgery. And 2) we had a patient with infiltrating SALs (No. 1) whose tumor was located in a lumbar segment (L5) and was completely in the ventral part. This is not common and has rarely been reported before ${ }^{9,16,22}$. We performed subtotal resection, and the longterm effect was good.

\section{Clinical syndromes}

The clinical syndromes of epidural angiolipomas are basically the same as those of other benign space-occupying spinal tumors ${ }^{20)}$. Because of the benign nature of angiolipomas and with the prolongation of the disease course, patients may gradually develop sensory disorders, weakness in the lower limbs and sphincter dysfunction.

Sudden deterioration of neurological symptoms can occur due to intratumoral hemorrhage or thrombosis ${ }^{11,19,27,30)}$. Patient No. 6 in our group experienced sudden aggravated radicular pain due to hemorrhagic SALs after receiving a back massage. The sudden intratumoral hemorrhage was confirmed by changes in imaging data and actual conditions during surgery. Additionally, these sudden deteriorating phenomena can occur during pregnancy and with a history of weight gain in obese patients, as reported elsewhere ${ }^{8,17,26,27)}$, probably because of hormonal changes and an increase in the fatty component of the tumor.

\section{Radiological manifestations and classification}

Lin and $\operatorname{Lin}^{15)}$ categorized SALs into noninfiltrating and infiltrating in 1974. MRI is the standard diagnostic tool for SALs. The fat content appears hyperintense on T1- and T2weighted images, has a weakened signal due to fat suppression, and has no enhancement performance, while the vascular

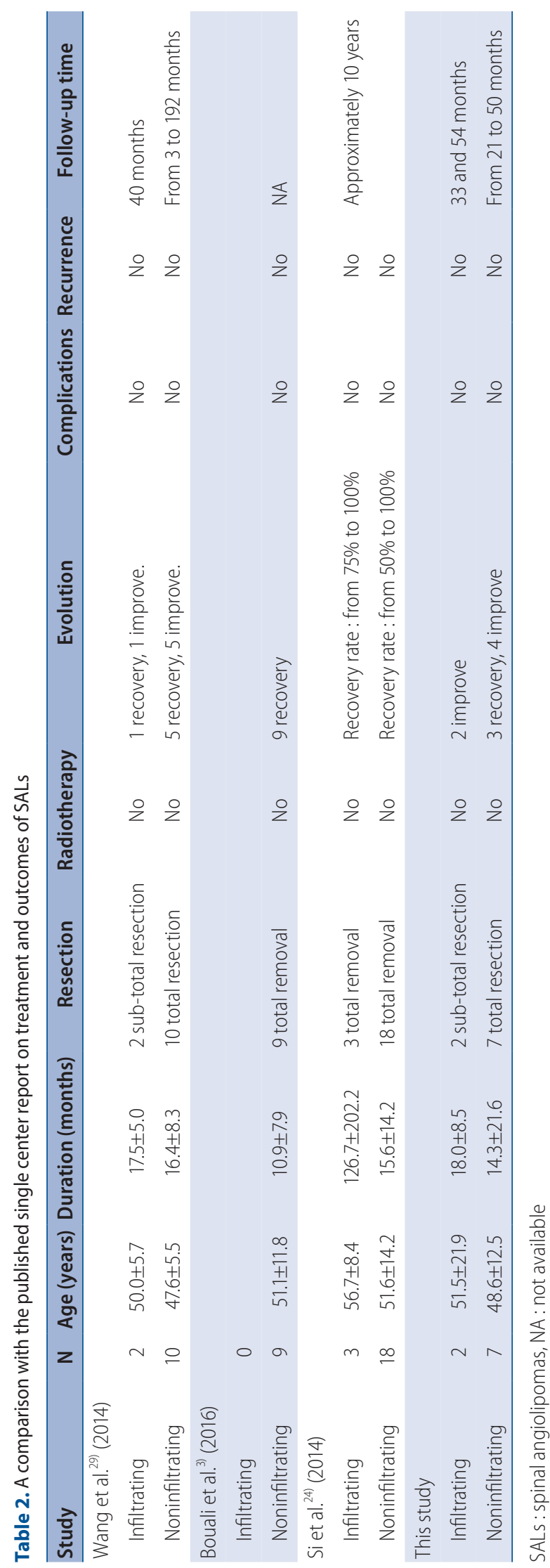


component appears isointense on T1-weighted images and hyperintense on T2-weighted images, is not weakened due to fat suppression and is strongly enhanced after the injection of contrast medium. Because SALs are composite tumors composed of mature fat tissue and proliferated vasculature, their appearance on MRI is often protean ${ }^{11)}$. Computed tomography scanning is helpful for evaluating the degree of bone destruction when the tumor infiltrates the vertebral body. Differential diagnoses include extradural lipomatosis, nerve sheath tumor, meningioma, metastasis, and malignant lymphoma.

Si et al. ${ }^{24)}$ proposed a new and impressive classification of SALs. According to their classification strategy, subtype IB SALs usually have lipomatosis in their upper and/or lower segments. In our patients, the MRI manifestations were consistent with those reported in most studies, but we did not observe any cases of lipomatosis in the upper and/or lower segments of the tumors, even in overweight patients. This could be because we had a limited number of cases.

\section{Pathology and diagnosis}

Histologically, SALs are tumors composed of mature lipocytes and proliferating abnormal vessels, including capillary, sinusoidal, venous or arterial vascular elements. The ratio of fat to vessels is variable, ranging from $1: 3$ to $2: 3^{15,21,29)}$. Immunohistochemical assays were performed in seven of our nine patients, and we observed positive staining for CD31, CD34, and S-100 and a low proliferation rate of Ki-67. The results were in agreement with those reported in the literature ${ }^{6,24,25)}$. A diagnosis of SALs should be based on a combination of clinical, radiological and pathological examination findings.

\section{Surgical plans and outcomes}

The extent of resection for infiltrative SALs has always been a topic of debate. Because patients' symptoms are caused by tumors in the spinal canal, surgeons generally do not deal with the affected vertebral bodies. Therefore, infiltration does not determine the choice of surgical procedure. In our opinion, the axial localization (dorsal or ventral) and the extent of intervertebral foramen involvement are the factors that should determine the surgical plan.

Most cases in which tumors are located dorsally and those in which the intervertebral foramens are not seriously affected can be totally resected. In such cases, we usually found that the tumors were compressive epidural fatty tissue intermingled with vascular structures that bled easily. Total resection was relatively easy to achieve without dura injury because adhesions between the tumors and the dura were limited.

However, if tumors are located ventrally, if the intervertebral foramens are seriously affected, or if the thoracic cavity is involved, wider resection should be planned. The extent of laminectomy should be appropriately expanded, especially on the symptomatic side. Additionally, according to Si et al. ${ }^{24)}$, the sternocostal joint might need to be removed in some cases. In these cases, surgeons can cut the tumors into pieces and remove them in a piecemeal fashion rather than in an intralesional fashion. For the cases whose facet joint were partially removed, and the cases whose sternocostal joint need to be removed, appropriate internal fixation is recommended to ensure spinal stability. Radiotherapy and chemotherapy are not recommended for these cases of subtotal resection.

According to the literature, most SALs patients have a good prognosis, even in cases of subtotal resection ${ }^{3,24,29)}$. According to the largest single center report, 21 cases of SALs had a good prognosis and no recurrence with a follow up of approximately 10 years $^{24)}$. As to Wang et al. ${ }^{29)}$, case series (12 cases of SALs), two cases of infiltrating SALs with subtotal resection had no recurrence with a mean follow-up of 40 months. The recurrence of SALs after surgery is rare, and only two cases were reported : one after gross-total removal ${ }^{2)}$ and one infiltrating tumor following subtotal resection ${ }^{12)}$. According to literature, the first case recurred 12 years after surgery ${ }^{2}$. A comparison with the published single center report on treatment and outcomes of SALs is listed in Table 2.

In our group, six cases (including two infiltrating SALs) achieved improved outcome rather than recovered. It may be related to the nerve root invasion by the tumor, the duration of symptoms and the timing of surgery. As to recurrence, all seven patients who underwent total tumor resection had good prognoses with a mean follow-up of 30.6 months, and there was no recurrence. The patient who underwent subtotal resection (patient No. 1) exhibited an improved outcome 54 months after the surgery, which was a relatively long follow-up period, with no obvious signs of recurrence. From our point of view, early surgical resection is recommended because of the improvement or recovery of symptoms after surgery and the extremely low recurrence rate. 


\section{CONCLUSION}

SALs are rare but well-defined benign tumors. In addition to clinical characteristics and radiological manifestations, the diagnosis of SALs depends strongly on pathological findings. Early surgical resection is recommended, and the specific procedures used should be determined by the axial localization (dorsal or ventral) and the extent of intervertebral foramen involvement. Most patients have a good prognosis, even in cases of subtotal resection.

\section{CONFLICTS OF INTEREST}

No potential conflict of interest relevant to this article was reported.

\section{INFORMED CONSENT}

This type of study does not require informed consent.

\section{AUTHOR CONTRIBUTIONS}

\author{
Conceptualization : XZ, GW \\ Data curation : SD, GW, HZ \\ Formal analysis : XZ, SD, GW, HZ \\ Funding acquisition : JJW, GW \\ Methodology : XZ, SD \\ Project administration : XZ, JJW, GW \\ Visualization : XZ, JJW \\ Writing - original draft : XZ, SD \\ Writing - review \& editing : JJW, GW
}

\section{ORCID}

$\begin{array}{ll}\text { Xiaolei Zhang } & \text { https://orcid.org/0000-0002-6431-0169 } \\ \text { Sheng Dong } & \text { https://orcid.org/0000-0002-0147-3286 } \\ \text { Guoqin Wang } & \text { https://orcid.org/0000-0002-6302-577X } \\ \text { Huifang Zhang } & \text { https://orcid.org/0000-0002-4011-8623 } \\ \text { James Jin Wang } & \text { https://orcid.org/0000-0001-6806-3524 } \\ \text { Guihuai Wang } & \text { https://orcid.org/0000-0002-9254-5088 }\end{array}$

\section{- Acknowledgements}

This work was supported by the Beijing Tsinghua Changgung Hospital Fund (Grant No. 12017C1026).

\section{References}

1. Anson JA, Cybulski GR, Reyes M : Spinal extradural angiolipoma: a report of two cases and review of the literature. Surg Neurol 34 : 173178,1990

2. Bender JL, Van Landingham JH, Manno NJ : Epidural lipoma producing spinal cord compression. Report of two cases. J Neurosurg 41 : 100103, 1974

3. Bouali S, Maatar N, Bouhoula A, Abderrahmen K, Said IB, Boubaker A, et al. : Spinal epidural angiolipomas: clinical characteristics, management and outcomes. Asian J Neurosurg 11 : 348-351, 2016

4. Fourney DR, Tong KA, Macaulay RJ, Griebel RW : Spinal angiolipoma. Can J Neurol Sci $28: 82-88,2001$

5. Garg A, Gupta V, Gaikwad S, Deol P, Mishra NK, Sharma MC, et al. : Spinal angiolipoma: report of three cases and review of MRI features. Australas Radiol 46 : 84-90, 2002

6. Gelabert-González M, García-Allut A : Spinal extradural angiolipoma: report of two cases and review of the literature. Eur Spine J 18 : 324335,2009

7. Groen RJ : Non-operative treatment of spontaneous spinal epidural hematomas: a review of the literature and a comparison with operative cases. Acta Neurochir (Wien) 146 : 103-110, 2004

8. Guegan Y, Fardoun R, Launois B, Pecker J : Spinal cord compression by extradural fat after prolonged corticosteroid therapy. J Neurosurg 56 : 267-269, 1982

9. Han SR, Yee GT, Choi CY, Lee CH : Infiltrating spinal angiolipoma. J Korean Neurosurg Soc 52 : 161-163, 2012

10. Howard WR, Helwig EB : Angiolipoma. Arch Dermatol 82 : 924-931, 1960

11. Hu S, Hu CH, Hu XY, Wang XM, Dai H, Fang XM, et al. : MRI features of spinal epidural angiolipomas. Korean J Radiol 14 : 810-817, 2013

12. Kujas M, Lopes M, Lalam TF, Fohanno D, Poirier J : Infiltrating extradural spinal angiolipoma. Clin Neuropathol 18 : 93-98, 1999

13. Labram EK, el-Shunnar K, Hilton DA, Robertson NJ : Revisited: spinal angiolipoma--three additional cases. Br J Neurosurg 13 : 25-9, 1999

14. Leu NH, Chen CY, Shy CG, Lu CY, Wu CS, Chen DC, et al. : MR imaging of an infiltrating spinal epidural angiolipoma. AJNR Am J Neuroradiol 24 : 1008-1011, 2003

15. Lin JJ, Lin F : Two entities in angiolipoma. A study of 459 cases of lipoma with review of literature on infiltrating angiolipoma. Cancer $34: 720$ 727, 1974

16. Nadi MM, Nadi AM, Zabara MY, Ahmad TM : Management of infiltrating spinal epidural angiolipoma. Neurosciences (Riyadh) 20 : 159163, 2015 
17. O'Donovan NA, Naik K, Maloney WJ, Llewellyn CG : Spinal angiolipoma mimicking extradural lipomatosis. Can Assoc Radiol J 47 : 51-53, 1996

18. Pagni $C A$, Canavero S : Spinal epidural angiolipoma: rare or unreported? Neurosurgery 31 : 758-764; discussion 764, 1992

19. Preul MC, Leblanc R, Tampieri D, Robitaille Y, Pokrupa R : Spinal angiolipomas. Report of three cases. J Neurosurg $78: 280-286,1993$

20. Provenzale JM, McLendon RE : Spinal angiolipomas: MR features. AJNR Am J Neuroradiol $17:$ 713-719, 1996

21. Reyes D, Candocia FJ : Thoracolumbar spinal angiolipoma demonstrating high signal on STIR imaging: a case report and review of the literature. Spine J 13 : e1-e5, 2013

22. Rocchi G, Caroli E, Frati A, Cimatti M, Savlati M : Lumbar spinal angiolipomas: report of two cases and review of the literature. Spinal Cord $42: 313-316,2004$

23. Samdani AF, Garonzik IM, Jallo G, Eberhart CG, Zahos P : Spinal angiolipoma: case report and review of the literature. Acta Neurochir (Wien) 146 : 299-302; discussion 302, 2004

24. Si Y, Wang Z, Pan Y, Lin G, Yu T : Spinal angiolipoma: etiology, imaging findings, classification, treatment, and prognosis. Eur Spine J 23 : 417425, 2014

25. Sim K, Tsui A, Paldor I, Kaye AH, Gaillard F : Four cases of spinal epidural angiolipoma. J Clin Neurosci 25 : 134-139, 2016

26. Trabulo A, Cerqueira L, Monteiro J, Roque P, Reis FC, Coelho MR : Spinal angiolipomas revisited: two case reports. Acta Neurochir (Wien) 138 : 1311-1319, 1996

27. Tsutsumi S, Nonaka Y, Abe Y, Yasumoto Y, Ito M : Spinal angiolipoma in a pregnant woman presenting with acute epidural hemorrhage. J Clin Neurosci 18 : 849-851, 2011

28. Turgut $M$ : Spinal angiolipomas: report of a case and review of the cases published since the discovery of the tumour in 1890. Br J Neurosurg $13: 30-40,1999$

29. Wang B, Yang Z, Yang J, Wang G, Xu Y, Liu P : Spinal angiolipoma: experience of twelve patients and literature. Neurol India $62: 367-370$, 2014

30. Zhang X, Wang JJ, Guo Y, Dong S, Shi W, Wang G, et al. : Sudden aggravated radicular pain caused by hemorrhagic spinal angiolipomas after back massage. World Neurosurg 134 : 383-387, 2020 